Revista de Matemática: Teoría y Aplicaciones 2009 16(2): 267-281

CIMPA - UCR ISSN: 1409-2433

\title{
ANALYSIS AND DESIGN OF THE KNOWLEDGE REPRESENTATION FOR THE IMPLEMENTATION OF A DISTRIBUTED REASONING
}

\author{
Martha Mora-TORRES* \\ Ana Lilia Laureano-Cruces ${ }^{\dagger}$

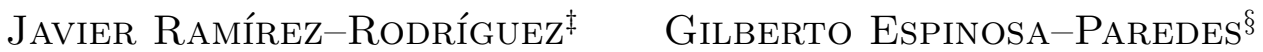

Recibido/Received: 20 Feb 2008 - Aceptado/Accepted: 9 Oct 2008

\begin{abstract}
The representation of knowledge and the reasoning comprise fundamental parts of the design of an expert system. In the case under study the real world is represented by the different events that can arise in the operation of a nuclear plant. These events are characterized by a set of elements interrelated through expert reasoning. We have chosen fuzzy cognitive maps (FCM) for the representation of the expert reasoning front to a fault event, because it handles the uncertainty in the decision making, through the interrelation among its elements. In addition, the FCM emphasizes a representation that allows parallel distributed reasoning (PDR). In our work we detail the analysis and design that was developed to build the causality matrices that give origin to the distributed reasoning, and ultimately have a representation in the FCMs.
\end{abstract}

Keywords: Fuzzy cognitive maps, parallel distributed reasoning, knowledge representation.

\section{Resumen}

La representación del conocimiento y el razonamiento forma parte fundamental del diseño del sistema experto. En el caso de estudio, el mundo real está representado por

\footnotetext{
* Maestría en Ciencia e Ingeniería de la Computación, IIMAS-UNAM, Circuito Escolar Ciudad Universitaria, 04510 México D.F., México. E-Mail: kabhun@yahoo.com.mx

${ }^{\dagger}$ Universidad Autónoma Metropolitana - Unidad Azcapotzalco, Departamento de Sistemas, Avenida San Pablo 180, 02200 México D.F., México. E-Mail: clc@correo.azc.uam.mx

${ }^{\ddagger}$ Universidad Autónoma Metropolitana - Unidad Azcapotzalco, Departamento de Sistemas, Avenida San Pablo 180, 02200 México D.F., México. E-Mail: jararo@correo.azc.uam.mx

${ }^{\S}$ Universidad Autónoma Metropolitana - Unidad Iztapalapa, Departamento de Ingeniería e Hidráulica, Av. San Rafael Atlixco 186, Col. Vicentina, 09340 México D.F., México. E-Mail: gepe@xanum.aum.mx
} 
268 M. Mora - L. Laureano - J. RAmíReZ - G. EspinOsA Rev.Mate.Teor.Aplic. (2009) 16(2)

\begin{abstract}
los distintos eventos que se pueden manifestar en la operación de la planta nuclear. Dichos eventos se caracterizan por un conjunto de elementos interrelacionados a través del razonamiento experto. Hemos elegido los mapas cognoscitivos difusos (MCD) para la representación del razonamiento experto frente a un evento de falla, debido a que éstos, logran manejar la incertidumbre en la toma de decisiones, a través de la interrelación de sus elementos, además de potenciar el razonamiento distribuido paralelo (RPD). En este trabajo se detalla el análisis y diseño de las matrices causales que dan origen al razonamiento distribuido, y que finalmente tienen una representación en los MCD.
\end{abstract}

Palabras clave: Mapas cognoscitivos difusos, razonamiento distribuido, representación del conocimiento.

Mathematics Subject Classification: 68T30, 68T37.

\title{
1 Introduction
}

The emulation of expert behavior needs, in addition to a representation technique, the careful determination of the expert knowledge and experience, including the uncertainty involved in the process. The usual techniques of elicitation of knowledge are not very good, because they ignore certain cognitive components, like the mental models, that are essential elements of the expert behavior [1,2].

The cognitive task analysis (CTA) allows obtaining the cognitive components of a task: factual knowledge, declaratory knowledge, procedural knowledge and, tactical and strategy knowledge, also the mental model of the cognitive task. The fundamental task of our case under study is expert decision making about emergency scenarios like the small loss of coolant accidents (small LOCA) [4,6]. This type of task fulfills most of the conditions under which Ryder and Redding [11] recommend the use of the CTA: 1 . The task of the case under study involves complexity in the problem and decision making. 2. The supervisor who operates the plant requires much attention to monitor the involved processes and parameters like temperature, pressure, water level, etc. 3. Supervisors receive great amounts of information (procedure guides, manuals, codes) necessary for their instruction. 4. The experts consider that certain aspects are difficult to state or to demonstrate. 5 . The task entails doubts because of the uncertainty associated to the process of making decisions facing risk scenarios like small LOCA. This uncertainty is shown in the security analysis represented in Figure 1.

\section{Domain}

The domain on which the CTA works consists of two front edges of defense that must be covered in a nuclear plant emergency, $i$. e., the reactor and the primary container. The chosen scenario is the one known as Small Loss Of Coolant Accident (Small LOCA), this being one of the most representative of accident scenarios $[3,6,13]$. Figure 2 shows the scenario and its consequences. 


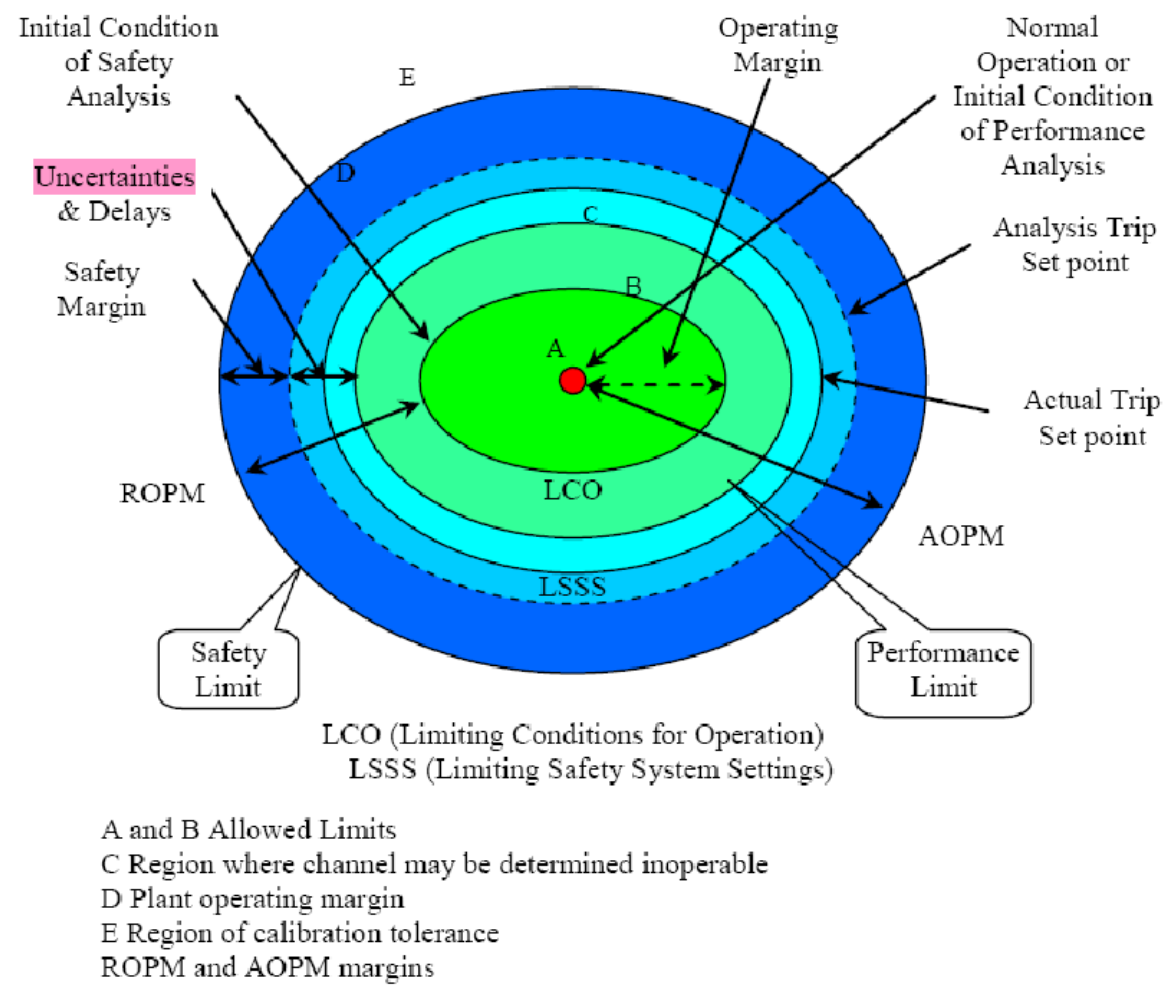

Figure 1: Conceptual diagram of SMART performance and security analysis [5].

To identify the best representation of a problem is an art and it is possible to learn it only in an intuitive way. Hard and fast rules do not exist that can frame in a quick and simple form an identification of the representation of the problem space.

\section{Understanding the problem}

The following elements are needed: Coherence, correspondence and relation. This consists of two basic steps: a) Identify the pertinent information from the description of the problem, to eliminate unnecessary information: One first generalized approach was obtained, shown in Figure 2; b) To organize a scheme of correct form: to attain a model of the cognitive conduct of the expert by the use of CTA. 


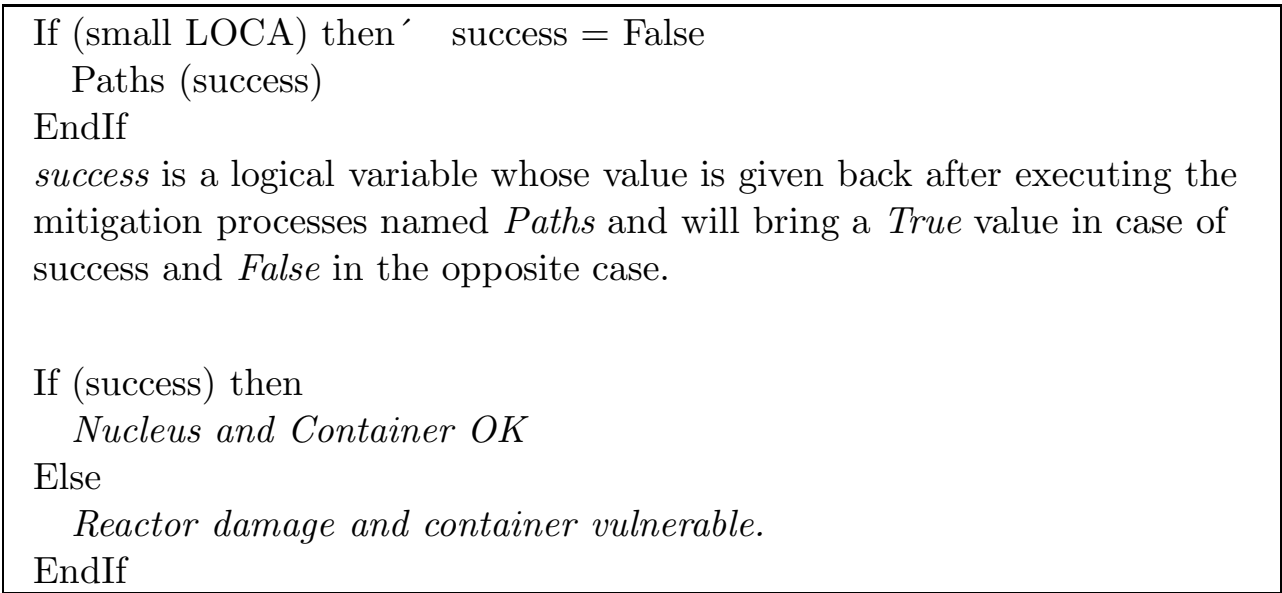

Figure 2: Paths of small LOCA scenario.

\section{Representation: Construction of the model using the CTA as an analysis tool}

Our work develops the CTA and the design of the knowledge representation, taking into consideration the following objectives: a) To analyze the expert conduct, in making decisions, to elicit the expert knowledge; b) To model the representation of the cognitive conduct of an expert, specifically the making of decisions in an emergency; c) To implement the cognitive model to simulate the expert conduct; and d) To develop a knowledge base (matrix of causality relations) that contains the approximate knowledge, trying to get the greater fidelity to the expert knowledge. In order to obtain these objectives, after developing the CTA, the cognitive model is designed using the FCMs as representations $[7,8,9,10,12,15]$, which results in: a) Identification of the nodes of the map; b) Establishment of relations between the nodes. c) Obtaining the map and matrix of relations and d) Choosing the threshold function. Finally, the tests and interpretation of results were made.

\subsection{Cognitive Task Analysis (CTA)}

This analysis is made by stages; in each stage the obtained models are refined. Understanding the scenario with the help of the experts and the literature they provided, allowed to divide it in three main parts: a) To identify the parameters that define the inputs to the emergency scenario, by means of parameter analysis; b) To determine the elements that take part in the operation of the main mitigation systems, like High Pressure Cool Spray (HPCS), when there is an emergency; and c) To identify other elements that take part in the mitigation of the effects of an emergency. To know how these elements interact allows attaining the success like a possible consequence of the mitigation of effects. This paper will deal only with the first part (the second part has already been reported in [13]). For more information see [14]. 
a) Analysis of Parameters: The parameters that are controlled in an emergency are identified by consulting the expert and the guides to emergency procedures $[4,6]$ :

- Vessel water level

- Vessel pressure

- Reactor power

- Suppression pool temperature

- Primary container pressure

- Dry well temperature

- Suppression pool water level

The reactor control procedure establishes three parallel courses of action, one for each of the parameters being controlled (vessel pressure, vessel level, and reactor power). Because the actions taken to control any of the parameters affect control over the others, the three parameters must be controlled concurrently; in other words, the water level in the reactor vessel cannot be stabilized and kept within a specific range if the pressure in the vessel is oscillating, and in turn the pressure in the vessel cannot be stabilized or controlled adequately if the reactor power is varying. The following actions to control the parameters focus on protecting the core and the primary container.

Core protection:

- Actions to control the water level in the vessel (establish proper cooling of the core, keeping it flooded).

- Actions to control the pressure in the vessel; stabilize the pressure helping to control the water level in the vessel and, if necessary, depressurizing and cooling the vessel to cold shutdown conditions.

- Action to control reactor power if SCRAM (emergency shutdown of a nuclear reactor) fails; lowers the reactor power with manual insertion of control rods and injection of boride.

Protection of the primary container:

- Actions taken to control any of the key parameters of the primary container (pressure, dry and wet well temperature, and wet well level) may directly affect control over other parameters, and therefore all actions are executed concurrently. Specifically, changes in: a) suppression pool temperature can directly cause changes in primary container pressure; b) dry well temperature can directly cause changes in primary container pressure; c) suppression pool directly cause changes in well pressure.

- If the suppression pool temperature remains below the value of the most restrictive limit operating condition no further operator action is needed. Then, the action is 
272 M. Mora - L. LAUREANO - J. RAMÍReZ - G. EsPinOSA Rev.Mate.Teor.Aplic. (2009) 16(2)

to continue the process of monitoring and controlling suppression pool temperature using available suppression pool cooling systems. The initial action taken to control the suppression pool water level uses the same methods typically used in normal plant operation: monitor its status and fill or drain the suppression pool as needed to keep the level within the limits given by Technical Specifications.

The expert conduct in the control actions is represented by the mental model of Figure 3. The mental model obtained shows the relations and the causality between the different concepts and elements that the expert handles to face an emergency like a small LOCA. Figure 3 shows the parameters and their conditions (stable or unstable) that determine the entrance or not of an emergency like a small LOCA. CTA analysis is summarized in a table that consists of the following columns $[1,11]$ : steps of the development, content of the steps, means of evaluation, type of representation and complexity of the processes that underlie the evaluation.

Thus we have the steps of the development of the mental model: to verify variations of parameters to determine if we are entering or not a small LOCA emergency. Table 1 includes the CTA and allows obtaining the essential elements to structure an expert system.

\begin{tabular}{l|cc}
\hline \hline Development Steps & Content Steps & Representation \\
\hline $\begin{array}{l}\text { 1. Verify variations of physical } \\
\text { parameters Step 1 }\end{array}$ & Factual & Structures \\
$\begin{array}{l}\text { 2. Determine whether or not we } \\
\text { are entering an emergency Step 2 }\end{array}$ & $\begin{array}{c}\text { Conceptual \& } \\
\text { procedural }\end{array}$ & $\begin{array}{c}\text { Structures \& } \\
\text { processes }\end{array}$ \\
\hline \hline
\end{tabular}

Table 1: CTA of the analysis of physic parameters.

A refinement of the CTA is produced with the purpose of obtaining with more detail the conceptual knowledge and the skills necessary to perform the tasks [11]. This analysis considers the work as a whole, where these skills can or cannot correspond to individual tasks, or to be part of a single task. The skills component is analyzed in Table 2; the tasks involved are shown as a sequence of steps. In the case where the procedure is cognitive, it is centered on the mental model, as in our case under study. If there are more underlying skills or knowledge, the table can be refined to such a degree that the tacit expert knowledge becomes explicit.

The procedural skills in Table 3 are necessary to verify the state of each one of the elements involved in each part of the analysis, to allow establishing if the parameters are varying in a normal or abnormal way, and if the mitigation systems are available. To apply the procedural skills allows having in time the knowledge necessary for the application of those interactive skills, needed to carry on the task of supervision and control of the operation. Here it is also necessary to establish the types of knowledge that are used, according to the type of actions to take. From the procedural knowledge, for example, basic actions or behaviors are derived. Based on the basic behaviors more sophisticated ones can be developed. The types of knowledge observed in Tables 1, 2, and 3 that can lead to actions 
If (PoolTempChanges or WellTempChanges) then

ContainerProssureChanges

EndIf

If (PoolLevelChanges) then

WellPressureChanges and WellTempChanges EndIf

If (ReactorPowerVaries) then

ContainerPressuerVaries

EndIf

If (ContainerPressuerOscillater) then

ContainerLevelUnstable

EndIf

If (ContainerLevelControlled) then

WellPressureControlled \& WellTempControlled \& NucleusOK EndIf

If (PoolTempUnstable) then UnstablePoolLevel \& UnstableContainer \& PossibleNucleusDamage Endif

Dealing with concurrent events, parallel trajectories of action are required. For that reason, up to here it is

If (PossibleNucleusDamage) then

ReactorPowerVaries

UnstableContainer

SmallLOCAEmergency

EndIf

Figure 3: Mental model of parameters analysis. 
274 M. Mora - L. LAUREANO - J. RAmíReZ - G. EsPinOSA Rev.Mate.Teor.Aplic. (2009) 16(2)

\begin{tabular}{l|lc}
\hline \hline Conceptual knowledge & $\begin{array}{l}\text { Interrelations, } \\
\text { Rules and } \\
\text { procedures }\end{array}$ & $\begin{array}{c}\text { Conceptual } \\
\text { representation } \\
(\mathrm{CR})\end{array}$ \\
\hline Physical parameters: & -Relation between tempera- & \\
temperature, pressure, & ture, pressure and pool, well & Steps \\
water and power levels. & and container water level & $1 \& 2$ \\
(Emergency procedure & -Relation between vessel water & \\
guides- EPGs) & level and reactor power & \\
\hline \hline
\end{tabular}

Table 2: CTA of the analysis of physic parameters (conceptual knowledge).

\begin{tabular}{c|lc}
\hline \hline Skills & Necessary knowledge & CR \\
\hline Procedural & $\begin{array}{l}\text {-Variations of physical parameters } \\
\text { Relations between the different } \\
\text { physical parameters: pressure, } \\
\text { temperature, water level, power }\end{array}$ & \\
$\begin{array}{c}\text { Procedural \& } \\
\text { Interactive }\end{array}$ & EPGs & Step 2 \\
\hline \hline
\end{tabular}

Table 3: CTA of the analysis of physical parameters (necessary skills).

are as follows: Factual knowledge: a) F1, type of physical parameters; b) F2, variations in physical parameters, and F3, cooling system status. Procedural knowledge: a) P1, how the different parameters are affected, and b) P2, when an emergency is declared. Actions: a) A1, analyze parameters, and b) A2, enter emergency.

The conceptual graph (CG) (obtained from CTA), is shown in Figure 5. In general, the CG shows the knowledge (of any type) grouped in islands and links that relate them. In our case, we only developed the properties of knowledge representation and their type of connection, as well as the order of presentation of the skills. The connections between the islands specify the relations and the input/output data that there will be between those islands and the different levels of abstraction, (which can or cannot exist) representing the execution of the expert system.

The development of the cognitive expert conduct can be seen in Figure 4 and it is obtained from the CG. The human expert determines if there is an emergency considering the emergency procedure guides (EPGs), and the state of physical parameters, by means of an analysis of parameters (level 1). This analysis considers the relations between the different parameters as well as the effect that each one of them produces on the rest. From these relations and effects, in conjunction with the EPGs it is determined if we are entering an emergency like a small LOCA (level 1). 


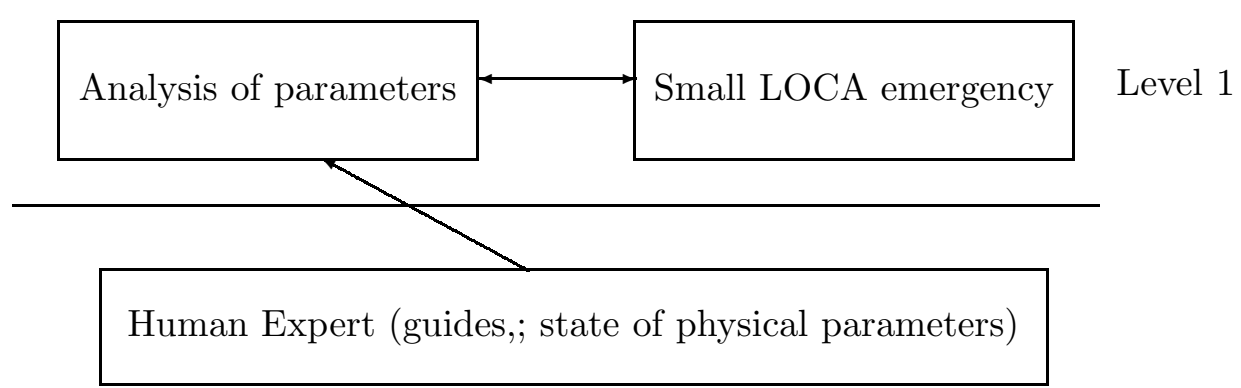

Figure 4: Behavioral diagram.
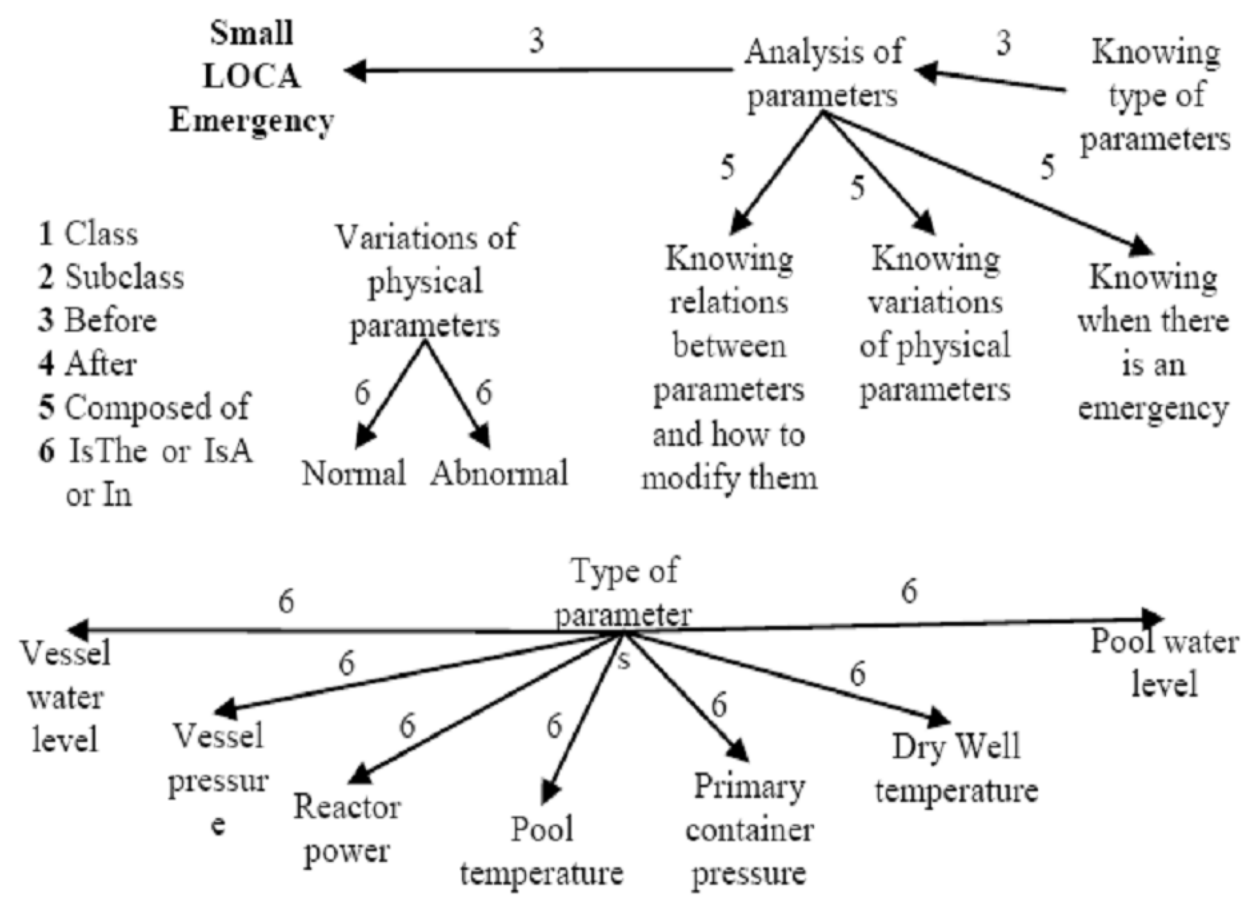

Figure 5: Conceptual diagram. 
276 M. MorA - L. LAUREANO - J. RAMÍReZ - G. EsPinOSA Rev.Mate.Teor.Aplic. (2009) 16(2)

\subsection{Fuzzy cognitive maps (FCM's)}

Fuzzy cognitive maps are used as a technique to represent the knowledge explicated by the CTA. These maps were introduced by Kosko [10] in 1986 to describe the behavior of a system in terms of concepts and causal relationships between such concepts. Kosko formalizes the causal relationship by proposing fuzzy causal relationships. One of the reasons for including fuzzy logic is to target a partially-focused relationship in relation to the operator "menor o igual que" between two nodes. Thus, according to Kosko, we have: $C_{i}=$ a concept, $Q_{i}=$ a set of linguistic tags (much, more or less, etc.) for $C_{i}, n=$ number of concepts, and $0<i \leq n$.

Then, for two concepts, $C_{i}$ and $C_{j}, C_{i}$ causes $C_{j}$ if

1. $Q_{i} \subset Q_{j}$ and $\neg Q_{i} \subset \neg Q_{j}$ (positive relationship),

2. $Q_{i} \subset \neg Q_{j}$ and $\neg Q_{i} \subset Q_{j}$ (negative relationship),

3. the numerical value of the causal relationship of $C_{i}$ to $C_{j}$.

To represent FCMs, we can also use a matrix of adjacency $(n x n)$, which includes the values of causal relationship between all the concepts. Kosko also includes a non-linear function. In other words, $E(n x n)$ is the matrix of a cognitive map and $C$ a given vector of system status at a given point in time. In this case $C_{i}$, which is the $i^{\text {th }}$ component of vector $C$, denotes the strength of the concept, from which the next status vector can be evaluated as: $C(t+1)=S[C(t) * E]$, where $S$ is a non-linear function applied individually to the components of the product of the matrix and $t$ denotes time.

It is important to bear in mind that including non-linearity sometimes forces the cognitive map to be recycled through the statuses.

An FCM, therefore, is a digraph that represents concepts as nodes and the causality relations between them are represented by edges (arrows). In order to show these causalities numerically, this edges take values within the range $(0,1]$ if the relations are positive, $[-1,0)$ if they are negative and 0 if it is neutral or has no effect $[7,8,9,10,12,15]$.

\subsection{Identification of Nodes}

The mental model shown on Figure 3 allows identifying the concepts, represented by nodes, that the expert behavior considers take part in or are affected during a possible emergency (Table 4).

\subsection{Establishing relations between the nodes}

In order to establish the causality relations between the different nodes, the cognitive analysis of the conduct of the expert was taken as a basis, specially the mental models and the conceptual graph obtained together with the expert and from CTA (section 4.1). This analysis was able to establish actions A1 and A2 considering the factual knowledge F1, F2 and F3, in addition to procedural knowledge P1 and P2. The relations are summarized in Table 5 . 


\begin{tabular}{l|l}
\hline \hline 1 & VWL (Vessel Water Level outside the acceptable range) \\
2 & VP (Vessel Pressure outside the acceptable range) \\
3 & RP (Reactor Power outside the acceptable range) \\
4 & SPT (Suppression Pool Temperature outside the acceptable range) \\
5 & DWT (Dry Well Temperature outside the acceptable range) \\
6 & PCP (Primary Contaioner Pressure outside the acceptable range) \\
7 & PWL (Pool Water Level outside the acceptable range) \\
8 & ROK (Reactor OK) \\
9 & SPC (Stabilized Primary Container) \\
\hline \hline
\end{tabular}

Table 4: Nodes identified in the mental model: Analysis of physical parameters.

\begin{tabular}{c|lc}
\hline \hline Actions & Causality relations & Value \\
\hline a) & Positive between SPT and PCP & 1 \\
b) & Positive between DWT and PCP, SPT and DWT, & 1 \\
& due to the relation both of them have with PCP & \\
c) & Implicitly negative between PWL and PCP & -1 \\
d) & Negative between VWL and VP & -1 \\
e) & Negative between VP and RP, RP and VWL & -1 \\
& because a higher water level in the container & \\
f) & (VWL) implies a diminution in RP & -1 \\
& Negative between VWL and ROK, VWL would & \\
g) & not guarantee an adequate cooling of the nucleus & -1 \\
h) & Negative between VP and ROK & -1 \\
i) & Negative between SPT and PWL & -1 \\
& PWL and SPC, SPC and PCP & -1 \\
j) & Negative between VWL and DWT & 1 \\
k) & Positive between SPC and ROK, RP and ROK & -1 \\
l) & Implicitly negative between SPT and RP \\
\hline \hline
\end{tabular}

Table 5: Relations found between the actions of the EPGs. 
278 M. Mora - L. Laureano - J. RAmíReZ - G. EspinOsA Rev.Mate.Teor.Aplic. (2009) 16(2)

\subsection{Causality map and matrix}

The representation of the model (Figure 6) is a matrix (Table 6) with the values of positive or negative causality between each one of the nodes and the rest, obtained from the analysis made with the expert's advice on the dominion and the CTA.

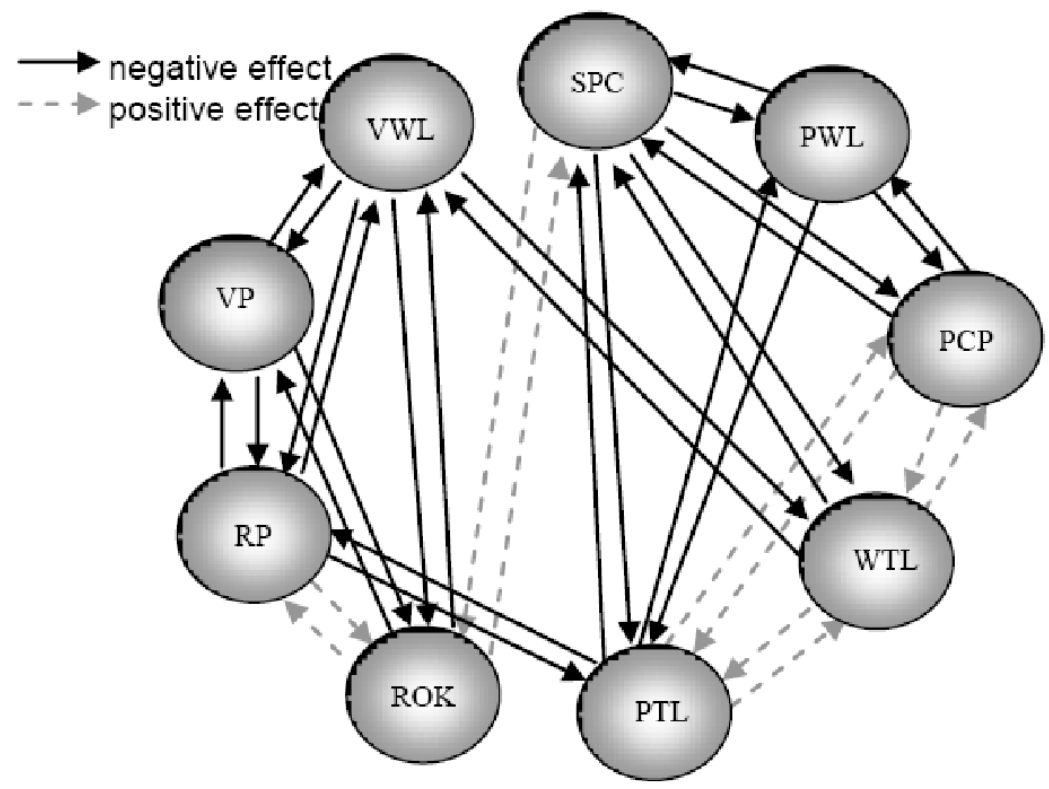

Figure 6: FCM of the analysis of physical parameters.

\begin{tabular}{c|ccccccccc}
\hline \hline & VWL & VP & RP & SPT & DWT & PCP & PWL & ROK & SPC \\
\hline VWL & 0 & -1 & -1 & 0 & -1 & 0 & 0 & -1 & 0 \\
VP & -1 & 0 & -1 & 0 & 0 & 0 & 0 & -1 & 0 \\
RP & -1 & -1 & 0 & -1 & 0 & 0 & 0 & 1 & 0 \\
SPT & 0 & 0 & -1 & 0 & 1 & 1 & -1 & 0 & -1 \\
DWT & -1 & 0 & 0 & 1 & 0 & 1 & 0 & 0 & -1 \\
PCP & 0 & 0 & 0 & 1 & 1 & 0 & -1 & 0 & -1 \\
PWL & 0 & 0 & 0 & -1 & 0 & -1 & 0 & 0 & -1 \\
ROK & 1 & -1 & 1 & 0 & 0 & 0 & 0 & 0 & 1 \\
SPC & 0 & 0 & 0 & -1 & -1 & -1 & -1 & 1 & 0 \\
\hline \hline
\end{tabular}

Table 6: Matrix of causality relations between the actions of the EPG. 


\subsection{Test scenario}

Each of the test scenarios has an initial vector (status of the nodes forming the FCM), the vectors resulting from the iterations indicated $\left(V_{1}-V_{8}\right.$ on average), and a final vector, whose value constitutes the status of each of the nodes in a future scenario. The results are interpreted by rounding off, applying the following criteria:

$S(x) \leq 0.337$, equal to 0

$0.455 \leq S(x) \leq 0.55$, equal to 0.5

$S(x) \geq 0.79$, equal to 1

where:

$$
\left\{\begin{array}{l}
0, \quad \text { the characteristic represented by the node is null } \\
0.5, \quad \text { the characteristic represented by the node is present } 50 \% \\
1, \quad \text { the characteristic represented by the node is present } 100 \%
\end{array}\right.
$$

Test scenario: The initial value of each node is indicated by the initial vector $\left(V_{i}\right)$. In this case, node SPT (Suppression Pool Temperature outside the acceptable range) is the only one with value 1 ; the other nodes are at zero.

\begin{tabular}{c|ccccccccc}
\hline \hline & VWL & VP & RP & SPT & DWT & PCP & PWL & ROK & SPC \\
\hline$V_{i}$ & 0 & 0 & 0 & 1 & 0 & 0 & 0 & 0 & 0 \\
\hline \hline
\end{tabular}

\begin{tabular}{|c|c|c|c|c|c|c|c|c|c|}
\hline & VWL & VP & $\mathrm{RP}$ & SPT & DWT & PCP & PWL & ROK & SPC \\
\hline V1 & 0.000000 & . 000000 & 0.000000 & 1.000000 & 0.000000 & 0.000000 & 0.000000 & 0.000000 & 0.000000 \\
\hline V2 & 0.500000 & 0.500000 & 0.006693 & 0.500000 & 0.993307 & 0.993307 & 0.006693 & 0.500000 & 0.006693 \\
\hline & $\ldots$ & $\ldots$ & ‥ & & & & & & \\
\hline V11 & 0.000238 & 0.136710 & 0.008831 & 0.999953 & 0.99995 & 0.999955 & 0.000045 & 0.186008 & 0.000002 \\
\hline V12 & 0.001283 & 0.273809 & 0.008540 & 0.999953 & 0.99995 & 0.999955 & 0.000045 & 0.345116 & 0.000001 \\
\hline Vf & 0.000292 & 0.144960 & 0.009474 & 0.999953 & 0.99995 & 0.999955 & 0.000045 & 0.208704 & 0.000002 \\
\hline
\end{tabular}

Table 7: Results of parameter analysis test 1.

Applying the rounding criteria we obtain the following final vector $\left(V_{f}\right)$ :

\begin{tabular}{c|ccccccccc}
\hline \hline & VWL & VP & RP & SPT & DWT & PCP & PWL & ROK & SPC \\
\hline$V_{f}$ & 0 & 0 & 0 & 1 & 1 & 1 & 0 & 0 & 0 \\
\hline \hline
\end{tabular}

The values 0 and 1 are interpreted as null and 100\% respectively for the process characteristic that the node, in particular, represents. This is a scenario where the nodes SPT (Suppression Pool Temperature), DWT (Dry Well Temperature), and PCP (Primary Container Pressure) take the value 1 , while the others take the value 0 , including nodes ROK (Reactor OK) and SPC (Stabilized Primary Container). This means that a dry well temperature outside the specified range causes a pressure outside the specified range in the primary container, which in turn results in destabilization of the primary container and reactor failure. 
280 M. Mora - L. Laureano - J. RAmíReZ - G. EspinOsA Rev.Mate.Teor.Aplic. (2009) 16(2)

\section{Conclusions}

Our work shows a dynamic methodology that allows analyzing the behavior of the expert through the different types of knowledge, actions and stimuli that interact with the environment. The former allows us to model faithfully the behavior relating all the elements, to be able to process all the actions as a whole, that is, in a parallel and distributed way through the FCMs. The advantage this technique offers is that it predictively provides the future scenario based on an initial failure, allowing mitigating actions to be defined automatically. This represents an aid in automating analysis of the decision-making process in risk situations, reducing human error without replacing human judgment in the process. Up to now, the results of the project have been favorable in the sense that they have been appraised by an expert.

Acknowledgment: this work is part of the research undertaken by Martha Mora-Torres, to obtain the Master of Engineering Degree in Computer Sciences and Engineering in IIMAS-UNAM, supported by CONACYT grant 210269.

\section{References}

[1] Castañeda, S. (2006) Evaluación del Aprendizaje en el Nivel Universitario, Elaboración de Exámenes y Reactivos-Objetivos. UNAM-Facultad de Psicología, Proyecto CONACYT 40608-H. México, D.F.

[2] De Arriaga-Gómez, F.; Laureano-Cruces, A.; Espinosa-Paredes, G. (2004) "Approximate reasoning for the implementation of the successive approximation method", CD Proceedings ISBN: 970-36-0155-3, XVII Congreso Nacional y III Congreso Internacional de Informática y Computación de la ANIEI, ANIEI, Tepic, Nayarit: 20-22.

[3] Glasstone, S.; Sesonske, A. (1994) Nuclear Reactor Engineering: Reactor Design Basics. Chapman \& Hall, New York, USA.

[4] González, M.; López, A.; Aguirre, A.; Marcos, J. (2001) "Guía técnica específica para elaboración de procedimientos de emergencia PSTG, revisión 6 para la unidad 1, revisión 2 para la unidad 2, por aumento de potencia y por combustible GE12 (basada en las EPGs revisión 4)", CFE y EMERSIS, México, D.F.

[5] Hee-Cheol, K. (2007) "Safety analysis", KAERI Nuclear Training Center http://www.kntc.re.kr/openlec/nuc/NPRT/module2/module2_3/

module2_3_1/2_3_1.htm

[6] Huerta, A.; Aguilar, O.; Núñez, A.; López, R. (1993) "Análisis de eventos internos para la unidad 1 de la central nucleoeléctrica de Laguna Verde: eventos iniciadores y secuencias de accidentes", Comisión Nacional de Seguridad Nuclear y Salvaguardias, México, D.F. 
[7] Khan, M.S.; Chong, A.; Quaddus, M. (1987) "Fuzzy cognitive maps and intelligent decision support -a review", School of Information Technology, Murdoch University, Graduate School of Business, Curtin University of Technology, GPO Box U.

[8] Konar, A.; Jain, L. (2005) Cognitive Engineering: A Distributed Approach to Machine Intelligence. Springer Verlag-London, U. K.

[9] Kosko, B. (1986) "Fuzzy cognitive maps", International Journal of Man-Machine Studies 24: $65-75$.

[10] Kosko, B. (1992) Neural Networks and Fuzzy Systems. A Dynamical Systems Approach to Machine Intelligence. Prentice-Hall, New Jersey

[11] Laureano-Cruces, A.; De Arriaga-Gómez, F.; García-Alegre, M. (2001) "Cognitive task analysis: a proposal to model reactive behaviors", Journal of Experimental $\mathscr{E}$ Theoretical Artificial Intelligence 13: 227-239.

[12] Laureano-Cruces, A.; Ramírez-Rodríguez, J.; Terán-Gilmore, A. (2004) "Evaluation of the teaching-learning process with fuzzy cognitive maps", Lecture Notes in Artificial Intelligence Series ISBN: 3-540-23806-9 3315: 922-931.

[13] Laureano-Cruces, A.; Ramírez-Rodríguez, J.; Mora-Torres, M.; Espinosa-Paredes, G. (2006) "Modeling a decision making process in a risk scenario: LOCA in a nucleoelectric plant using fuzzy cognitive maps", Research in Computing Science 26: 3-13.

[14] Mora-Torres, M. (2007) Sistema Experto en la Toma de Decisiones de un Escenario de Riesgo: LOCA Pequeño en una Planta Nucleoeléctrica. Tesis de Maestría en Ingeniería de la Computación, Instituto de Investigaciones en Matemáticas Aplicadas y en Sistemas - UNAM, México, D. F. http://delfosis.uam.mx/〜ana/

[15] Peláez, C.E.; Bowles, J.B. (1996) "Using fuzzy cognitive maps as a system model for failure modes and effects analysis", Information Sciences Elsevier Science 88: 177-199. 